\begin{tabular}{lll}
\hline Bentham open & The Open Sports Sciences Journal \\
\hline CrossMark & Content list available at: www.benthamopen.com/TOSSJ/ & DOI: $10.2174 / 1875399 \times 01710010251$ \\
\hline
\end{tabular}

RESEARCH ARTICLE

\title{
Equation to Fat Percentage Estimation in Women with Reduced Bone Mineral Density
}

Cristiane da Silva Oselame ${ }^{1, *}$, Gleidson Brandão Oselame ${ }^{2}$, Oslei de Matos ${ }^{3}$ and Eduardo Borba Neves $^{4}$

${ }^{I}$ Federal Technological University of Paraná. Av. Sete de Setembro, 3165 - Rebouças CEP, 80230-901 - Curitiba - PR Brasil.

${ }^{2}$ Federal Technological University of PR Av. Sete de Setembro, 3165 - Rebouças CEP 80230-901 - Curitiba - PR Brasil. Home address: Rua Mariano Torres, 958, apto 905, Curitiba, Brasil.

${ }^{3}$ Federal Technological University of Paraná. Av. Sete de Setembro, 3165 - Rebouças CEP 80230-901 - Curitiba - PR Brasil.

${ }^{4}$ Biomedical Engineering, Lecturer in Graduate Program in Biomedical Engineering from the Federal Technological University of Paraná.. Av. Sete de Setembro, 3165 - Rebouças CEP, 80230-901 - Curitiba - PR - Brasil.

\section{Abstract:}

\section{Introduction:}

The measurement of body fat is a way to obtain information about the characteristics that can lead to a framework of certain diseases. Thus, women in postmenopausal period experience significant variations in the body composition and fat distribution.

\section{Objective:}

To develop an equation to estimation of the body fat percentage in women with osteopenia / osteoporosis based on anthropometric measurements easily obtainable.

\section{Methods:}

The sample consisted of 74 women participating in the study group of the Physical Exercise Program for Osteoporosis Federal Technological University of Paraná, all in postmenopausal period and with osteopenia or osteoporosis. It evaluated body composition and bone mineral density by absorptiometry Radiological Dual Energy (DXA), anthropometry and body circumferences (waist, abdomen and hips), and nutritional status by the Body Mass Index (BMI) as the World Health Organization classification.

\section{Results:}

The sample can be characterized by the following average data: age of $59.32 \pm 6.96,27.14 \pm 3$ BMI 90, Waist Hip Ratio of $0.85 \pm$ 0.08 and Body fat percentage $40.35 \pm 4.04$. The proposed equation was Body Fat Percentage $(\mathrm{BFP})=14,419+(0.405 \mathrm{x}$ BMI $)+$ (0.147 x HC) using only two predictor variables, BMI and hip circumference (PQ).

\section{Conclusion:}

The standard error of estimate of the proposed equation was $2.89\left(\mathrm{R}^{2}=0.501\right)$ can be considered low average values for the percentage of fat in this population, suggesting that the equation can be used to estimate the percentage of body fat in postmenopausal women.

\footnotetext{
* Address correspondence to this author at the Federal Technological University of Paraná, Av. Sete de Setembro, 3165-Rebouças CEP, 80230-901 Rodovia BR 116, n 17906, Xaxim, Curitiba, Paraná, Brasil, Tel: (41)88413490; E-mail: cristianeoselame@gmail.com
} 
Keywords: Fat Percentage, Bone Mineral Density, Women, Postmenopausal, Osteoporosis.

\section{INTRODUCTION}

Osteoporosis is a skeletal disorder associated with decreased mass and deterioration of bone microarchitecture [1]. Diagnosis is performed by Bone Mineral Density (BMD) analysis [2]. Some world data indicate that osteoporosis affects more than 75 million people and it is estimated that by 2020 more than 10 million women will have the disease [3]. The incidence of osteoporosis is from $35 \%$ to $52 \%$ in women over fifty years, generating a treatment worth over $\$ 1$ billion per year [3]. Some risk factors are known: lifestyle, endocrine status, genetic factors, surgery, medicines and dietary habits [4].

As osteoporosis, obesity is considered a chronic disease with high prevalence in the world population. In this regard, the association between obesity and bone mass is described some time ago. It is suggested that environmental and genetic factors act in the same direction for bone and fat mass [5]. Physical educators, personal trainers and coaches need to pay attention to changes in body composition of their clients and athletes. These changes can lead prove fruitful or to pathological situations [6]. Thus, besides the loss of bone mass in postmenopausal period, women still experience significant variations in body composition and distribution of fat. The association between weight gain, muscle mass loss, increased body fat and changes in bone mass still has controversial results reported in the scientific literature [7]. However, the body weight is considered an important determinant of BMD. The increased weight leads to increased mechanical strength in the bone and consequent reduction of bone resorption [7].

The body fat measurement is one tool for assessing the risk to development of metabolic and cardiovascular diseases. There are many methods and techniques used for the assessment of body composition and estimation of the body fat percentage [8]. Among them, it can cite: anthropometry (skinfolds); body volume / density (hydrostatic weighing and plethysmography); bioimpedance (bioelectrical impedance); Picture / Attenuation X-ray / Infrared rays (radiation dual beam absorptiometry, computed tomography, magnetic resonance, ultrasound) and multi-compartment model (equations) [9].However, most of these methods require expensive technological resources, which prevents the frequent monitoring of body composition in large population groups.

In this sense, the present study aimed to propose an equation to estimate body fat percentage for women with osteopenia / osteoporosis based on anthropometric measurements easily obtainable.

\section{METHODS}

The sample consisted of 74 women who were participating in the exercise program of study group Physicians for Osteoporosis (PEFO) in the Federal Technological University of Paraná (UTFPR), all were in postmenopausal period and having osteopenia or osteoporosis.

The assessment of body composition and bone mineral density were done by Absorptiometry Radiological Dual Energy (DXA), performed with equipment from Hologic QDR ${ }^{\mathrm{TM}} 4500$ model Discovery. For anthropometric assessment were included: weight, height, waist circumference, waist circumference and hip circumference. Weight was measured using a digital scale brand Wiso with W910 model, capacity $180 \mathrm{~kg}$, graduation 100 grams with tempered glass platform, LCD screen, automatic activation to step on the scale and auto power off in 15 seconds. To weight measure, volunteers were barefoot and wearing only light clothing fabric type mesh (unadorned usage, buttons, bra, zipper and clothes with jeans fabric or similar).

Height was measured with a device Wiso ${ }^{\circledR}$ with measuring range $0-210 \mathrm{~cm}$, tape type with retractable spring, resolution in millimeters and numbering for every centimetre. This device was put at the wall to perform the height measurement in the upright position at the time of respiratory inspiration. For the evaluation of body circumferences (waist, abdomen and hips) was used the same device Wiso ${ }^{\circledR}$. During the waist circumference measurement, the tape was placed around the smallest circumference between the ribs and the iliac crest. For abdomen measuring tape was placed two fingers below the navel point. The measurement of the hip circumference was carried out by positioning the tape around the hips at the most protuberant area.

The characterization of nutritional status from the IMC followed the World Health Organization classification used by the mostly of authors of this domain $[10,11]$ : normal weight (BMI $>18.5$ and $<25)$, overweight (BMI $\geq 25$ and $<30$ ) and obesity (BMI $\geq 30 \mathrm{~kg} / \mathrm{m}^{2}$ ).

The study followed the ethical aspects recommended by Resolution 466/2012 on research involving human subjects 
and was approved by the Research Ethics Committee under CAAE number:. 21751513.0.0000.5547 on 13/02/2014. Descriptive data are presented as mean and standard deviation. The model was built from the linear regression. For determination of the predictor variables was used the Pearson correlation coefficient. All analyses were performed using the Software Statistical Package for Social Sciences 21. The confidence interval was set at 95.00\% $(p<0.05)$.

\section{RESULTS}

The sample consisted of 74 women diagnosed with osteopenia or osteoporosis, in postmenopausal period. The sample profile is presented in Table $\mathbf{1}$.

Table 1. Characteristics of women diagnosed with osteopenia / osteoporosis in postmenopausal $(\mathrm{n}=\mathbf{7 4})$, Curitiba, Brazil, 2015.

\begin{tabular}{|c|c|c|c|c|}
\hline Variables & Minimum & Maximum & Average & Standard Deviation \\
\hline Age (years) & 46,00 & 79,00 & 59,32 & 6,96 \\
\hline Height (m) & 1,43 & 1,75 & 1,57 & 0,06 \\
\hline Weight (kg) & 45,50 & 103,30 & 67,25 & 11,15 \\
\hline BMI & 19,42 & 37,81 & 27,14 & 3,91 \\
\hline Waist circumference $(\mathrm{cm})$ & 61,00 & 131,00 & 88,03 & 12,00 \\
\hline Hip circumference $(\mathrm{cm})$ & 72,00 & 127,00 & 101,35 & 9,79 \\
\hline WHR & 0,69 & 1,03 & 0,85 & 0,08 \\
\hline BMDFemur $\left(\mathrm{g} / \mathrm{cm}^{2}\right)$ & 0,53 & 0,82 & 0,67 & 0,07 \\
\hline BMDColumn $\left(\mathrm{g} / \mathrm{cm}^{2}\right)$ & 0,66 & 1,06 & 0,83 & 0,08 \\
\hline BodyFat Percentage $(\%)$ & 29,20 & 49,00 & 40,35 & 4,04 \\
\hline
\end{tabular}

Where: $\mathrm{BMI}=$ body mass index; WHR = waist-hip ratio; $\mathrm{BMD}=$ bone mineral density.

To test the correlation between anthropometric variables, we proceeded to the Pearson test. Table 2 shows the results of analysis.

Table 2. Pearson correlation for the anthropometric variables $(n=74)$, Curitiba, Brazil, 2015.

\begin{tabular}{|c|c|c|c|c|}
\hline Variables & $\mathrm{HC}$ & WC & IMC & $\%$ Fat \\
\hline $\mathrm{HC}$ & - & $0,791 *$ & $0,819^{*}$ & $0,673^{*}$ \\
\hline WC & $0,791 *$ & - & $0,822 *$ & $0,604^{*}$ \\
\hline IMC & $0,819^{*}$ & $0,822^{*}$ & - & $0,677^{*}$ \\
\hline \begin{tabular}{|l} 
DXA BF\% \\
\end{tabular} & $0,673^{*}$ & 0,604* & $0,677^{*}$ & - \\
\hline
\end{tabular}

Where: DXA BF\% = Body Fat Percentage by Absorptiometry Radiological Dual Energy, HC = Hip Circumference; WC = Waist Circumference; $\mathrm{BMI}=$ Body Mass Index. ${ }^{*} \mathrm{p}<0.01$.

Afterwards, we proceeded to the linear regression between the percentage of fat variables and anthropometric data. Table 3 expresses the results of the analysis to the equation proposed to achieve the goal of the present study.

Table 3. Linear regression analysis of results for equations to estimate the percentage of fat per anthropometric variables.

\begin{tabular}{|c|c|l|l|}
\hline Number of Variables & \multicolumn{1}{|c|}{$\mathbf{R}^{2}$} & \multicolumn{1}{|c|}{ Standard error of estimate } & \multicolumn{1}{|c|}{ Predictors } \\
\hline 7 & 0,517 & 2,9662 & Constant + WHR, Height, Age, BMI, HC, WC and Weight \\
\hline 3 & 0,501 & 2,9208 & Constant + HC, WC and BMI \\
\hline 2 & 0,501 & 2,8989 & Constant + HC and BMI (Equation 1) \\
\hline
\end{tabular}

Where: WHR = Waist-Hip Ratio; BMI = Body Mass Index; HC = Hip Circumference; WC = Waist Circumference

Equation 1 expresses the relationship between the variables to obtain the estimated body fat percentage from the $\mathrm{BMI}$ and HC.

$$
\mathrm{BF} \%=14,419+(0,405 \times \mathrm{IMC})+(0,147 \times \mathrm{PQ})
$$

Where: $\mathrm{BF} \%=$ Body fat percentage, $\mathrm{BMI}=$ body mass index, $\mathrm{HC}=$ hip circumference.

Table 4 shows the statistical characteristics of the each predictor used in Equation 1.

Table 4. Statistics features of the proposed model for body fat percentage estimation using BMI and HC (Equation 1). 


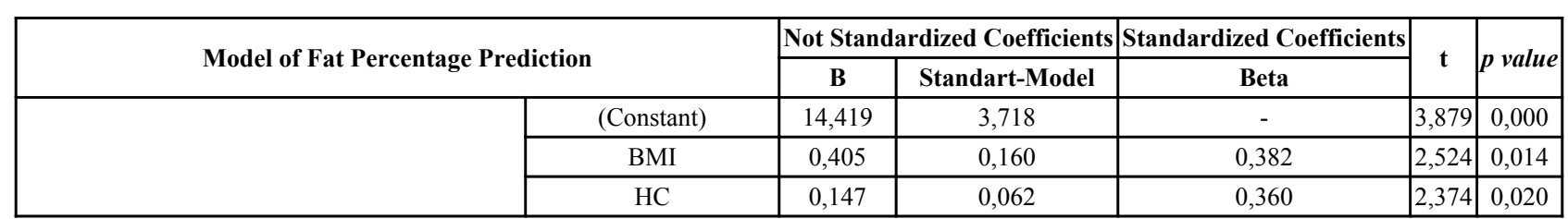

Where: $\mathrm{BMI}=$ Body Mass Index; $\mathrm{HC}=$ Hip Circumference.

\section{DISCUSSION}

The statistical parameters of the proposed equation were: 2.89 of standard error and a $\mathrm{R}^{2}=0.501$. This equation was developed using anthropometric variables of fast and easy acquisition. Some authors published a study [7]which aimed to develop an equation for predicting body fat by analysing variables related to skinfold thickness, using as reference the DXA, based in a group of 29 women with osteopenia / osteoporosis aged between 67 and 84 years. They used skinfolds various sites such as: biceps, triceps, subscapular and supra-iliac. The authors proposedan equation with standard error of $0.7 \%$ and $0.4 \mathrm{~kg}$. Although the estimate by skinfolds can be more accurate than those conducted by the equation proposed (Equation 1), the acquisitions of skinfold measurement are more complex and dependent on the calibration of equipment and evaluators expertise. Thus, the equation proposed appears to be easier to use when you need to monitor large numbers of people to more frequent monitoring of body composition of this population in specific.

In the study conducted by Castro et al. [8], aimed to verify that the body fat percentage estimated for six equations compared to DXA, based in a group of 46 healthy women with an average age of $65.9( \pm 8.0)$. The equations used the following anthropometric variables prediction: BMI, Arm Circumference (AC), waist circumference (WC) and Abdominal Circumference (AC) [12 - 15].All equations were strongly correlated with DXA, but with poor correlation among methods [8].The worst agreement with DXA was expressed by the equation proposed by Tran and Weltman [15], considering the circumference of the abdomen and hip, getting a percentage error variation between -30.43 to 1.47.The best results were expressed by equations of Lean et al. [14], considers that the arm circumference and age, with a percentage error variation between -24.93 to 14.48. Further, the equation of Movsesyan et al. [12], with percentage error variation between -26.21 to 11.6 .

The estimation of body fat percentage by skinfold thickness is limited, in obese people, by the difficulty in the skinfolds grip (separation of the muscle and the subcutaneous fat layer). Still, variables related to evaluator's ability, the type of compass used, the compressibility of adipose tissue and the patient's hydration level can influence the measurement precision [16]. On the other hand, just the measure of BMI leads to an overestimate body fat in active individuals and underestimate body fat in sedentary, obese, elderly and some clinical condition, despite his widely use in nutrition status assessment $[8,16]$.

In a cross-sectional study conducted by Sampaio e Figueiredo [17] were evaluated 634 patients (316 adults and 318 elderly) of both sexes, by measurement of: weight, height, triceps and subscapular skinfold thickness and waist and hip circumferences. The aim was to evaluate the correlation between body mass index and fat distribution, in adults and elderly. It is noteworthy in this study that BMI was positively and strong correlated with waist circumference in both age groups and in both sexes. However, BMI is less strongly correlated with WHR group, mainly in elderly women $(\mathrm{r}=$ $0.34 ; \mathrm{p}<0.001)$.

In the study of Andrade et al. [18], whose objective was to investigate the relationship between BMI and body fat percentage measured by bioelectrical impedance, which is not a 'gold standard' to this mensuration. The study tested the usage of age and BMI to estimate the body fat percentage, proposing an equation with a $\mathrm{R}^{2}=0.663(\mathrm{p}<0.001)$. In this study, we used the DXA to assess body fat percentage which is considered 'gold standard' for assessing body composition. The equation proposed in this study obtained a small standard error of estimate $\left(2.89\right.$ with $\left.\mathrm{R}^{2}=0.501\right)$.

As regarding to limitations of this study, we did not have acquired others circumferences such as: arm circumference and leg circumference, that maybe could improve the precision of the estimation' results.

\section{CONCLUSION}

The proposed equation 'body fat percentage $(\mathrm{BF} \%)=14,419+(0.405 \mathrm{x} \mathrm{BMI})+(0.147 \mathrm{x} \mathrm{PQ})$ ' used just two predictor variables, BMI and PQ (hip circumference), which are easily measured and little influenced by experience the evaluator, resulting in an easy and reproducible protocol. This equation can help physical educators, personal trainers and coaches to monitor changes in body composition of their clients and athletes. The standard error of the estimate of 
the proposed equation was $2.89\left(\mathrm{R}^{2}=0.501\right)$. It can be considered down to average values of fat percentage of this population.

\section{ETHICS APPROVAL AND CONSENT TO PARTICIPATE}

Approved by the Research Ethics Committee (Brazil) under CAAE number:. 21751513.0.0000.5547 on 13/02/2014.

\section{HUMAN AND ANIMAL RIGHTS}

No animals were used for this study. All humans research procedures performed in the current study were in accordance with the ethical standards of the institutional and/or national research committee and with the 1964 Helsinki declaration and its later amendments or comparable ethical standards .

\section{CONSENT FOR PUBLICATION}

Written informed consent was obtained from of all participants.

\section{CONFLICTS OF INTEREST}

The authors declare no conflict of interest, financial or otherwise.

\section{ACKNOWLEDGEMENTS}

Declared none.

\section{REFERENCES}

[1] Carvalho M, Kulak CA, Borba VZ. Prevalência de hipercalciúria em mulheres na pós-menopausa com osteoporose. Arq Bras Endocrinol Metabol 2012; 56(1): 1-5.

[http://dx.doi.org/10.1590/S0004-27302012000100001] [PMID: 22460188]

[2] Silva A C V, Da Rosa M I, Fernandes B, Lumertz S, Diniz R M, dos Reis Damiani M E F. Fatores associados à osteopenia e osteoporose em mulheres submetidas à densitometria óssea 2014.

[3] Dourado CM. Densidade mineral óssea em idosos e presença de fatores de risco nutricionais para osteoporose. Porto Alegre: Dissertação, Programa de Pós Graduação em Gerontologia Biomédica, Pontifícia Universidade Católica do Rio Grande do Sul 2012.

[4] Herdina SR. Atividade física e sua implicação sobre a densidade mineral óssea de mulheres na menopausa. Florianópolis: Dissertação, Programa de Pós-Graduação em Educação Física, Universidade Federal de Santa Catarina 2012.

[5] Bandeira F. A obesidade realmente fortalece os ossos? Arq Bras Endocrinol Metabol 2007; 51(6): 895-7. [http://dx.doi.org/10.1590/S0004-27302007000600001] [PMID: 17934654]

[6] Hughes VA, Frontera WR, Roubenoff R, Evans WJ, Singh MA. Longitudinal changes in body composition in older men and women: Role of body weight change and physical activity. Am J Clin Nutr 2002; 76(2): 473-81. [PMID: 12145025]

[7] Aniteli T, Florindo A, Pereira R, Martini L. Desenvolvimento de equação para estimativa da gordura corporal de mulheres idosas com osteoporose e osteopenia através da espessura de dobras cutâneas tendo como referência absorciometria por dupla emissão de raios X. Rev Bras Med Esporte 2006; 12: 366-70. [http://dx.doi.org/10.1590/S1517-86922006000600013]

[8] Castro EA, Lima LM, Amaral JF, Cerqueira MS, Doimo LA. Comparação entre equações estimativas e DXA para avaliação da gordura corporal em mulheres não sedentárias. Motricidade 2012; 8: 348-56.

[9] Souza RG, Gomes AC, Prado CM, Mota JF. Métodos de análise da composição corporal em adultos obesos. Rev Nutr 2014; 27 : 569-83. [http://dx.doi.org/10.1590/1415-52732014000500006]

[10] Neves EB, Ripka WL, Ulbricht L, Stadnik AM. Comparison of the fat percentage obtained by bioimpedance, ultrasound and skinfolds in young adults. Rev Bras Med Esporte 2013; 19: 323-7. [http://dx.doi.org/10.1590/S1517-86922013000500004]

[11] Neves EB. Prevalence of overweight and obesity among members of the Brazilian army: Association with arterial hypertension. Cien Saude Colet 2008; 13(5): 1661-8.

[http://dx.doi.org/10.1590/S1413-81232008000500029] [PMID: 18813666]

[12] Movsesyan L, Tankó LB, Larsen PJ, Christiansen C, Svendsen OL. Variations in percentage of body fat within different BMI groups in young, middle-aged and old women. Clin Physiol Funct Imaging 2003; 23(3): 130-3. [http://dx.doi.org/10.1046/j.1475-097X.2003.00464.x] [PMID: 12752553]

[13] Deurenberg P, Weststrate JA, Seidell JC. Body mass index as a measure of body fatness: Age- and sex-specific prediction formulas. Br J Nutr $1991 ; 65(2): 105-14$. 
[http://dx.doi.org/10.1079/BJN19910073] [PMID: 2043597]

[14] Lean ME, Han TS, Deurenberg P. Predicting body composition by densitometry from simple anthropometric measurements. Am J Clin Nutr 1996; 63(1): 4-14. [PMID: 8604668]

[15] Tran ZV, Weltman A. Generalized equation for predicting body density of women from girth measurements. Med Sci Sports Exerc 1989; 21(1): 101-4

[http://dx.doi.org/10.1249/00005768-198902000-00018] [PMID: 2927293]

[16] Lutoslawska G, Malara M, Tomaszewski P, et al. Relationship between the percentage of body fat and surrogate indices of fatness in male and female Polish active and sedentary students. J Physiol Anthropol 2014; 33: 10. [http://dx.doi.org/10.1186/1880-6805-33-10] [PMID: 24887103]

[17] Sampaio LR, Figueiredo VD. Correlação entre o índice de massa corporal e os indicadores antropométricos de distribuição de gordura corporal em adultos e idosos. Rev Nutr 2005; 18: 53-61. [http://dx.doi.org/10.1590/S1415-52732005000100005]

[18] Andrade FT, De Carvalho MC, Dos Santos MA, Torres-Leal FL, Ferreira AH. Estimativa do percentual de gordura utilizando o IMC. RBONE-Revista Brasileira de Obesidade, Nutrição e Emagrecimento 2014; 8: 142-7.

(C) 2017 Oselame et al

This is an open access article distributed under the terms of the Creative Commons Attribution 4.0 International Public License (CC-BY 4.0), a copy of which is available at: (https:/creativecommons.org/licenses/by/4.0/legalcode). This license permits unrestricted use, distribution, and reproduction in any medium, provided the original author and source are credited. 